Weed Science 2017 65:107-114

(C) Weed Science Society of America, 2016

\title{
Influence of Soil Moisture Stress on Vegetative Growth and Mycorrhizal Colonization in Hound's-tongue (Cynoglossum officinale)
}

\begin{abstract}
Mina Momayyezi and Mahesh K. Upadhyaya*
Hound's-tongue is an invasive, biennial weed that thrives in dry rangelands of British Columbia. Rosette formation in the first year of growth and a deep root system offer this weed a competitive advantage against associated grasses under dry conditions. To study effects of water stress on seedling growth and mycorrhizal colonization in hound's-tongue, seedlings of this weed were grown in pots in a greenhouse and subjected to four $(100,80,60$, and $40 \%$ of field capacity) soil moisture treatments. Effects of soil moisture stress (SMS) on several growth parameters as well as mycorrhizal colonization of roots were studied. The total biomass, shoot and root fresh and dry weights, leaf number, petiole length, leaf area, and specific leaf weight (leaf dry weight per unit leaf area) decreased with increasing SMS; shoot and root water content was not affected. Because of a greater effect of SMS on root compared with the shoot biomass, shoot:root ratio increased as the moisture stress increased. Water stress decreased mycorrhizal colonization and arbuscule and vesicle abundance. A reduction in total biomass, leaf number and leaf area per plant, petiole length, and mycorrhizal colonization may reduce the competitive advantage of hound's-tongue over its neighbors under drought conditions. The effect on plant size may also influence herbivory, by biocontrol agents and other herbivores, and fecundity of this weed.
\end{abstract}

Nomenclature: Hound's-tongue, Cynoglossum officinale L.

Key words: Drought, mycorrhizae, rangeland weed, water stress.

Soil moisture stress (SMS) is a major factor limiting plant productivity in dry rangelands of British Columbia. Response to SMS depends on the species, stage of the life cycle, and the severity of stress. Plant species use a variety of mechanisms to deal with this stressor (Bray 1997; Chaves et al. 2002; Hsiao 1973). Knowledge of how SMS influences growth parameters of a species, which could impact its interaction with biotic and abiotic environments, is important to understanding its performance under drought conditions.

Hound's-tongue (family Boraginaceae) is a biennial or short-lived perennial weed, a native of Eurasia and Asia. This invasive weed is found in several provinces of Canada and thrives mostly under dry rangeland conditions (Boorman and Fuller 1984; Upadhyaya et al. 1988; Upadhyaya and Cranston 1991). In addition to competition for resources and allelopathic influence (Furness et al. 2008), which could reduce yield of associated grasses, this weed contains pyrrolizidine alkaloids, which are poisonous to livestock (Baker et al. 1989;

DOI: $10.1614 /$ WS-D-16-00058.1

*First and second authors: Graduate Student and Professor, Faculty of Land and Food Systems, University of British Columbia, Vancouver, BC V6T 1Z4, Canada. Corresponding author's E-mail: mina.momayyezi@alumni.ubc.ca
Knight et al. 1984; Upadhyaya and Cranston 1991). Rosette formation in the first year of establishment and a deep root system provide competitive advantage to this weed against associated grasses under dry rangeland conditions. Upadhyaya and Furness (1994) studied effects of SMS on hound's-tongue leaf-surface morphology and reported that neither the abundance nor the morphology of trichomes on leaf surface plays any significant role in acclimation of this weed to drought conditions. Beyond this research, little information is available on how SMS influences various growth parameters of hound'stongue that could influence its interaction with associated species.

The term "mycorrhiza" refers to a symbiotic relationship between a plant and a soil-borne fungus in which the plant provides resources for growth of the fungus, which in turn helps the plant acquire water and nutrients from the soil. Mycorrhizal fungi play an important role in uptake of nutrients (particularly phosphorus), stimulate plant growth and productivity, increase drought tolerance and subsequent recovery from water stress, improve water use efficiency and the ability of plants to extract water from the soil, and offer protection against soil-borne pathogens (Barea et al. 2005; Boomsma and Vyn 2008; Kaya et al. 2003; Johansson et al. 2004; Subramanian et al. 1995). SMS has been reported to 
influence mycorrhizal colonization in some but not all plant species (Busso et al. 2008; Wu and Xia 2006). While it has been reported that hound's-tongue is a mycorrhizal weed (Pendleton and Smith 1983), whether SMS influences colonization of roots of this weed by arbuscular, vesicular mycorrhizal fungus is not known.

The objectives of this study were: (1) to study effects of SMS on important vegetative growth parameters of hound's-tongue and (2) to determine whether SMS influences mycorrhizal colonization of this weed. This information is necessary to improve our understanding of the ecophysiology of this serious rangeland weed.

\section{Material and Methods}

Hound's-tongue nutlets collected at Lethbridge, $\mathrm{AB}\left(49.69^{\circ} \mathrm{N}, 112.84^{\circ} \mathrm{W}\right)$ were soaked in water for 2 to $3 \mathrm{~h}$, and a dissecting needle was used to remove the pericarps and seed coats from the embryos. The embryos were placed on two 11-cm-diameter Whatman No.1 filter disks wetted with $2 \mathrm{ml}$ of deionized distilled water in $9 \mathrm{~cm}$ petri dishes for 48 to $72 \mathrm{~h}$ under laboratory conditions. Seedlings with $\geq 5$-mm-long radicles were planted in 14-cm-diameter pots containing a sandy-loam potting soil with $6 \%$ organic matter in the Horticulture Greenhouse of the University of British Columbia, Vancouver, BC $\left(49.26^{\circ} \mathrm{N}, 123.25^{\circ} \mathrm{W}\right)$ under natural light supplemented with highpressure sodium lamps $\left(10 \mathrm{~h} \mathrm{~d}^{-1}\right.$; minimum photosynthetically active radiation: $400 \mu \mathrm{E} \mathrm{m}^{-2} \mathrm{~s}^{-1}$ ) and at 22 to $28 \mathrm{C}$ temperature. Seedlings were thinned to one per pot and given SMS treatments starting at the third true-leaf stage, as described in the following section. Natural, soil-borne spores were the source of mycorrhizal inoculum.

SMS Treatments. Hound's-tongue seedlings were given four SMS (100, 80, 60, and $40 \%$ of field capacity [FC]) treatments. To determine the soil moisture content at the $\mathrm{FC}, 300 \mathrm{~g}$ (four replications) soil was watered to saturation (point of no additional water absorption) and drained for $24 \mathrm{~h}$, and its percent moisture content was calculated by weighing it before and after drying at $60 \mathrm{C}$ for $72 \mathrm{~h}$. The amount of soil moisture to achieve 80, 60, and $40 \%$ FC was calculated, and the various soil moisture treatments were achieved by adding an appropriate amount of water to a fixed weight of soil. The soil moisture content at 100, 80, 60, and $40 \%$ FC was approximately $0.348,0.191,0.126$, and $0.084 \mathrm{~m}^{-3}$ water $\mathrm{m}^{-3}$ soil, respectively. The soil water content during the experiment was measured using a ProCheck soil moisture sensor (Decagon Devices, Pullman, WA) every second day during the experiment, and water was added as necessary to maintain the desired moisture levels.

\section{Preparation of Roots for Observing Mycor-} rhizae. Hound's-tongue rosettes were harvested 8 wk after the start of SMS treatments. The roots were separated from the shoots and washed thoroughly under running tap water to remove soil. To measure mycorrhizal colonization, roots were cut into $2 \mathrm{~cm}$ fragments, placed in 50 by 30 by $5 \mathrm{~mm}$ plastic cassettes (TRUFLOW Biopsy Cassettes, Fisher Scientific, Toronto, ON), and boiled in $10 \% \mathrm{KOH}$ for 3 to $5 \mathrm{~min}$. The cassettes were washed under tap water, immersed in $3 \% \mathrm{HCl}$ for $2 \mathrm{~min}$, and washed under running tap water and then with deionized distilled water. The roots were removed from the cassettes and stained with $0.05 \%$ trypan blue (Sigma-Aldrich, St. Louis, MO) in deionized distilled water, glycerol, and lactic acid (1:1:1) solution (Cao et al. 2013; Gange et al. 1999). The stained roots were observed under a Leica DM750 microscope (40x; Leica Microsystems, Concord, $\mathrm{ON}$ ), and mycorrhizal colonization and percent arbuscule and vesicle abundance were measured using the scoring procedure described by Trouvelot et al. (1986). There were 10 replications of one plant each per treatment. Mycorrhizal colonization and arbuscule and vesicle abundance in five 2-cm-long root segments from each plant were recorded, and averages were calculated.

\section{Effect of SMS on Hound's-tongue Growth.}

Plant, root, and shoot fresh biomass were recorded. Roots and shoots were weighed before and after drying at $60 \mathrm{C}$ for $48 \mathrm{~h}$ to measure their dry biomass, and the percent moisture content was calculated. Leaf number per plant was recorded. Leaf greenness (three readings per plant for the youngest true leaf), leaf area per plant, and petiole length were measured using a SPAD-502Plus chlorophyll meter (Konica Minolta Optics, Ramsey, NJ), a leaf area meter, and a Vernier calliper, respectively. The SPAD-502Plus determines leaf greenness, an indicator of relative chlorophyll content, by measuring leaf absorbance in blue ( 400 to $500 \mathrm{~nm}$ ) and red (600 to $700 \mathrm{~nm}$ ) wavelength regions. The specific leaf weight (SLW; dry leaf biomass $[\mathrm{g}]$ per leaf area $\left[\mathrm{cm}^{2}\right]$ ) was calculated.

108 - Weed Science 65, January-February 2017 
A completely randomized design with 10 replications of one plant each per SMS treatment was used. The experiment was conducted twice. All data were subjected to analysis of variance using the general linear model (GLM) procedure of the SAS software (version 9.2; SAS Institute 2009). Data were checked for normality and uniformity of variance and were transformed as needed. Multiple mean comparisons were run using the GLM procedure of SAS ( $\mathrm{P}=0.001$, Bonferroni adjustment) and the $P$ value was adjusted for the number of $t$-tests. Since there were significant treatment by experiment interactions for most of the parameters observed, results of both experiments are presented.

\section{Results and Discussion}

Effect of Soil Moisture Level on Plant Growth. Hound's-tongue plant fresh biomass decreased with decreasing soil moisture level $(\mathrm{P} \leq 0.001)$ (Figure 1A). Compared with $100 \%$ FC, plants at 40 and $60 \% \mathrm{FC}$ were 87 and $70 \%$ smaller on a fresh biomass basis in experiment 1 and $84 \%$ and 60\% smaller in experiment 2 , respectively. While the plants in experiment 2 were shorter compared with experiment 1, effects of soil moisture level on plant shoot and root biomass were generally similar. SMS reduced hound's-tongue plant biomass due to reductions in both the shoot and the root biomass; both shoot and root fresh and dry weights decreased with decreasing soil moisture level $(\mathrm{P} \leq 0.001)$ (Figure 1B, C). Interestingly, as soil moisture level decreased, the shoot to root biomass ratio (S:R) increased significantly. S:R of hound's-tongue plants grown at $100,80,60$, and $40 \% \mathrm{FC}$ were $0.35,0.61$, 1.00 , and 1.41 , respectively, in experiment 1 , and $0.50,0.82$. 0.91 , and 1.44 , respectively, in experiment 2 . This suggests that the reduction of hound'stongue root dry biomass with increasing SMS was much greater compared with that of the shoot dry biomass, resulting in an increase in the S:R ratio. Except for a significant $(\mathrm{P} \leq 0.001)$ reduction in shoot water content at $40 \%$ FC compared with all other SMS treatments in experiment 2, soil moisture level did not influence the shoot or root water content (Figure 2).

The leaf area and the number of leaves per plant decreased as soil moisture level decreased from 100 to $40 \%$ FC $(\mathrm{P} \leq 0.001)$ (Figure $3 \mathrm{~A})$. In both experiments, the plants grown under $40 \% \mathrm{FC}$ had $38 \%$ shorter petioles compared with those grown at $100 \%$ FC $(\mathrm{P} \leq 0.001)$ (Figure 3B). The SLW was
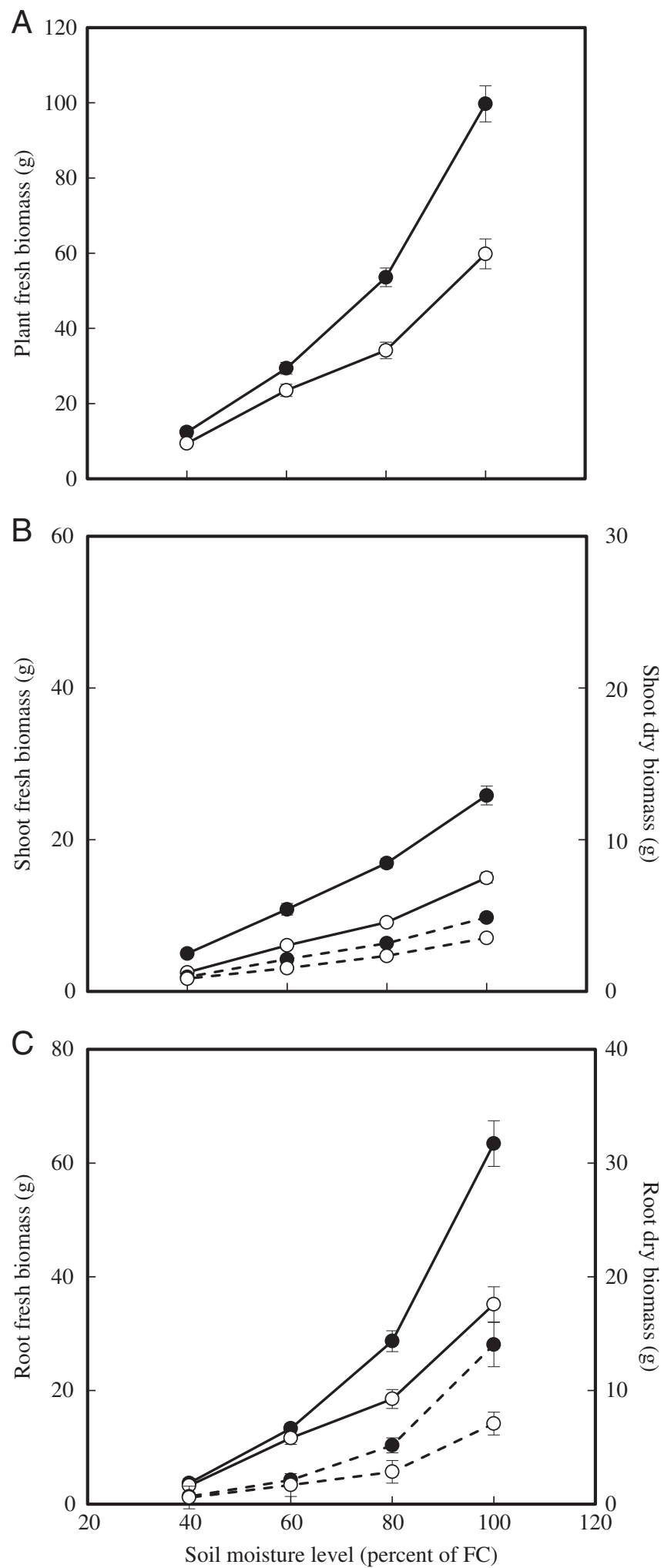

Figure 1. Effect of soil moisture level (\% of FC) on hound's-tongue (A) plant, (B) shoot, and (C) root fresh (-) and dry (- . - -) biomass; (•) and (०) indicate results of experiments 1 and 2, respectively. Values are means $\pm \mathrm{SE}$ of 10 replicates of one plant each.

lower for plants grown under $40 \%$ FC compared with $100 \%$ FC in both experiments $(\mathrm{P} \leq 0.001)$ (Figure 3C). The leaf greenness (chlorophyll meter 

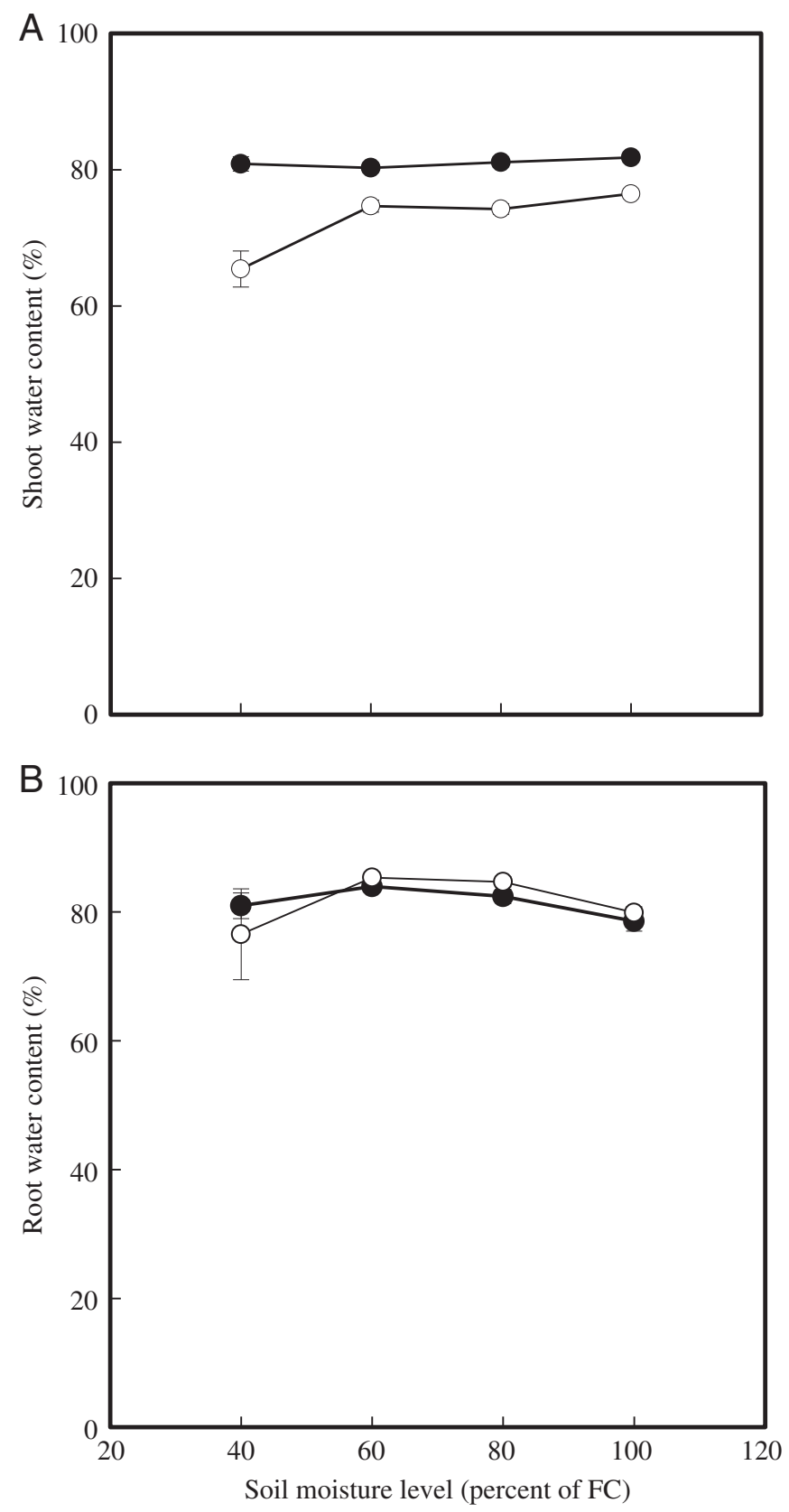

Figure 2. Effect of soil moisture level (\% of FC) on (A) shoot and (B) root water content of hound's-tongue plants; $(\bullet)$ and $(\mathrm{O})$ indicate results of experiments 1 and 2, respectively. Values are means $\pm S E$ of 10 replicates of one plant each.

reading) for plants grown under $100 \%$ FC was slightly lower compared with those at $80 \%$ FC, but this decline was significant $(\mathrm{P} \leq 0.001)$ only in experiment 2 (Figure 3D). Since experiment 1 of this study was conducted in July and August, and experiment 2 was conducted in October and November, the difference in plant growth in the two experiments could be due to the difference in light intensity, day length, and temperature conditions between the summer (July and August) and fall (October and November) in Vancouver, BC.
The day length dropped from 14 to $10 \mathrm{~h}$ from August to October and the greenhouse temperature from 28 to $22 \mathrm{C}$.

Hound's-tongue is a serious rangeland weed of $\mathrm{BC}$ and some other parts of the world (Upadhyaya and Cranston 1991; Upadhyaya et al. 1988). It infests relatively sunny and dry regions of $\mathrm{BC}$ (Upadhyaya et al. 1988). Success of this weed under dry rangeland conditions has been attributed to its deep root system, which provides a competitive advantage against shallow-rooted grasses. The effects of SMS on early hound's-tongue growth reported in this study have several ecological implications for this weed under dry rangeland conditions. The plants with lower leaf area and shorter petiole are expected to be less competitive because of their lower canopy coverage to shade shorter associated species (Tremmel and Bazzaz 1993, Weijschedé et al. 2006). In addition to impacting the dominance of hound's-tongue over other species, water stress could also impact survival and distribution of this weed in rangelands. De Jong and Klinkhamer (1988) reported a positive correlation between survival of hound's-tongue seedlings and water content in the top $10 \mathrm{~cm}$ of soil under field conditions; seedling survival was found to improve upon watering. They suggested that soil moisture availability was one of the main factors in determining the spatial distribution of hound's-tongue in the coastal sand dunes of Meijendel, the Netherlands. However, in our pot-culture, greenhouse experiments, no plant mortality was observed. Because effects of environmental factors during the juvenile phase of plant development are important in determining subsequent survival, distribution, and domination of adult plants, we limited our investigation to only the first 8 wk of the hound's-tongue life cycle. Even a small advantage during this phase can be pivotal in determining the subsequent success of this weed. Smaller plants produced at high SMS (40 and 60\% FC) are also expected to produce a fewer seeds per plant, which may impact the persistence of this weed.

Plant size has been reported to be related to aboveground herbivory (Rowell-Rahier 1984; Tiritilli and Thompson 1988; van der Meijden et al. 1988). In a study of the relationship between hound's-tongue plant size and root herbivory by the root weevil Ceuthorhynchus cruciger, Prins et al. (1992) found that attacks by this insect pest were highly size dependent. Weevils preferred larger compared with smaller plants; a higher percentage of flowering plants were infested as the root crown 


\section{A}

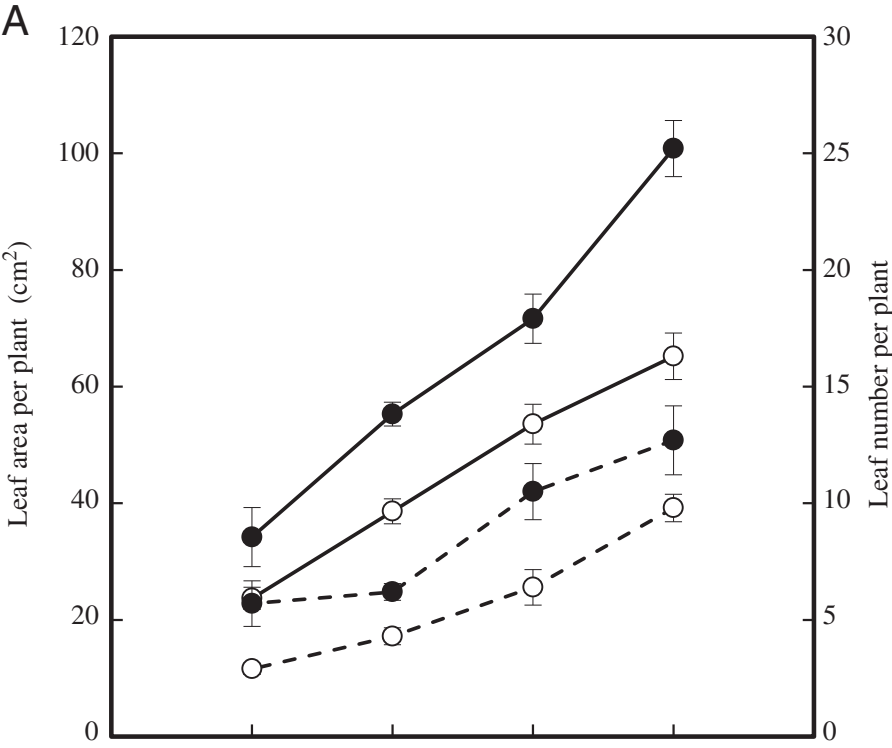

C

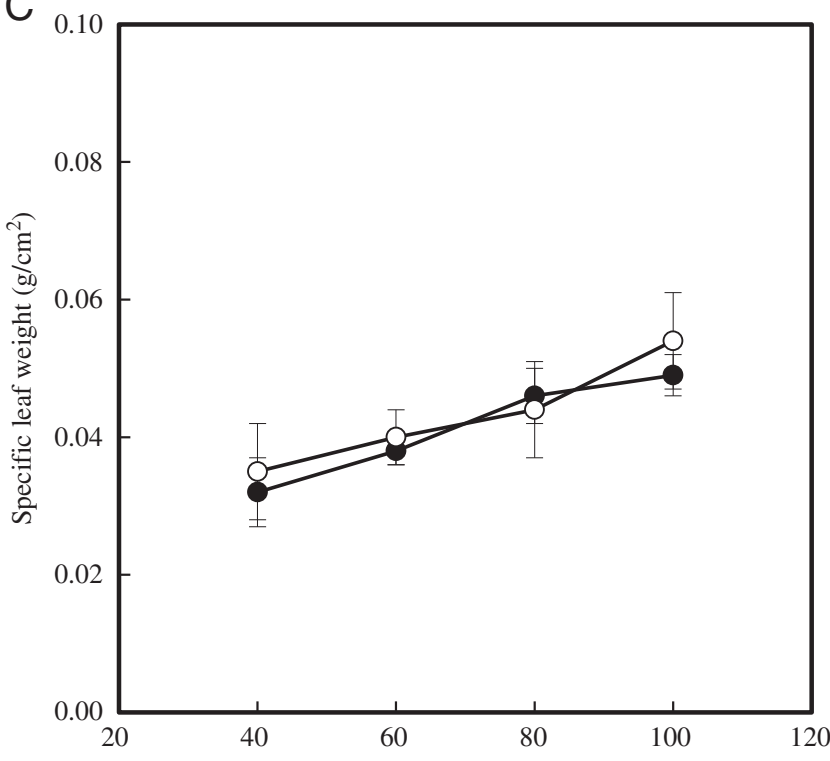

B

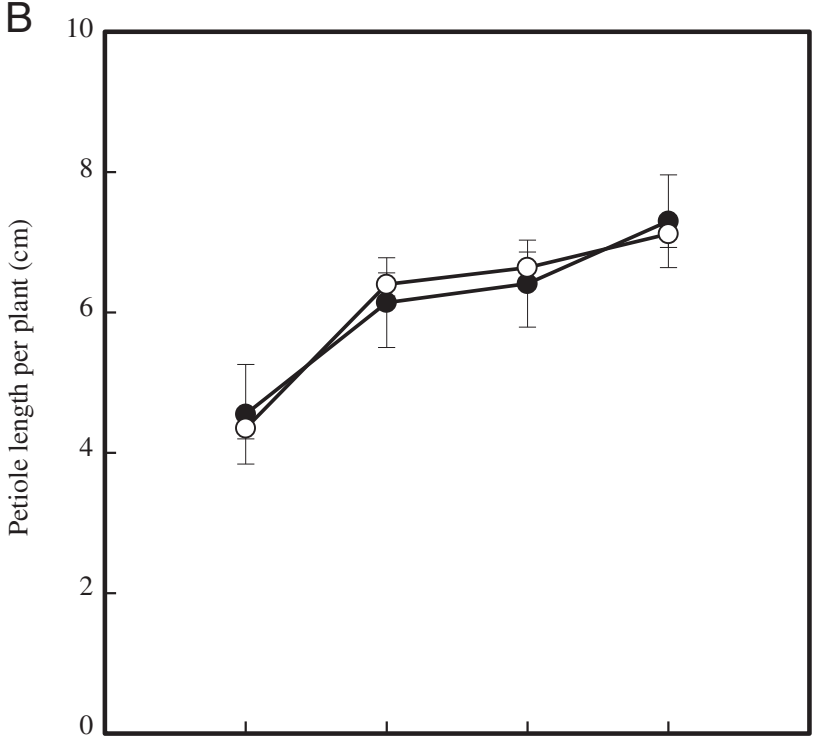

$\mathrm{D}$

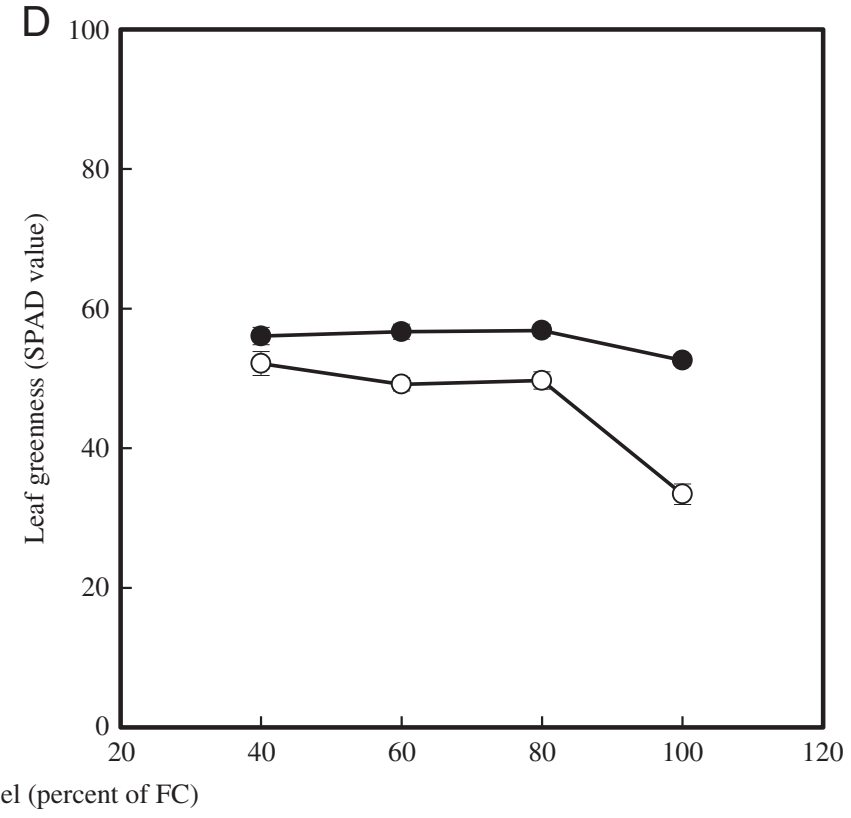

Figure 3. Effect of soil moisture level (\% of FC) on hound's-tongue (A) leaf area ( - ) and leaf number (- - - -) per plant, (B) petiole length, (C) specific leaf weight, and (D) leaf greenness (chlorophyll meter reading); $(\bullet)$ and $(\circ)$ indicate results of experiments 1 and 2 , respectively. Values are means \pm SE of 10 replicates of one plant each.

diameter increased. Weevil attack significantly reduced seed production in terms of both number and weight of seeds per unit plant weight. Larger hound's-tongue plants produced at higher FCs are therefore expected to attract more herbivores, which could influence resource allocation for seed production. Water stress has been reported to influence feeding and oviposition by beet army worm (Spodoptera exigua) in Palmer amaranth pigweed (Moran and Showler 2005). Changes in leaf chemistry can influence insect feeding, growth, and/or reproduction (Mattson and Haack 1987; White 1984).
We have found that SMS influences feeding preference and the biomass of grasshoppers feeding on hound's-tongue leaf disks, which could be related to the increase in leaf disk $\mathrm{N}$ content with increasing SMS (Momayyezi 2012).

Rosette leaves of hound's-tongue have been reported to contain high concentrations of the pyrrolizidine alkaloids heliosupine, acetyl-heliosupine, and echinatine (Knight et al. 1984; Upadhyaya et al. 1988). Concentration of these alkaloids, which are responsible for livestock poisoning, can reach as high as $2.1 \%$ on the dry weight basis. These alkaloids also 

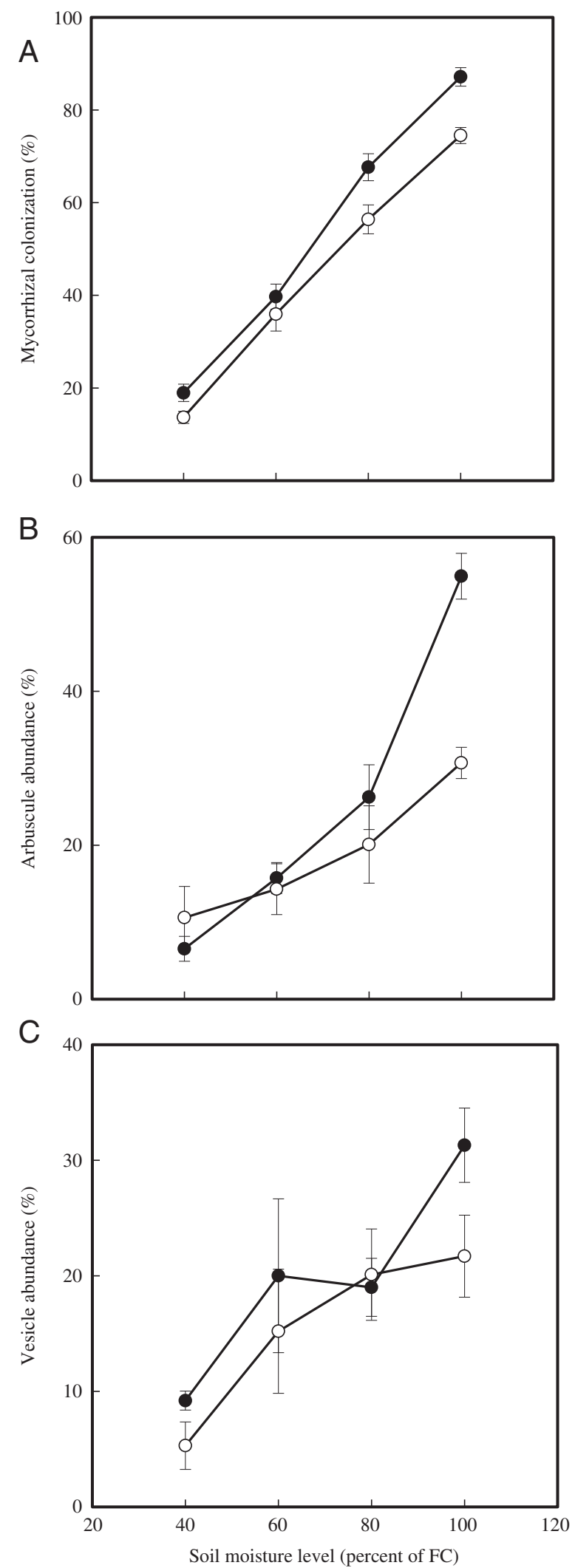

Figure 4. Effect of soil moisture level (\% of FC) on (A) mycorrhizal colonization and (B) arbuscule and (C) vesicle abundance in the mycorrhizal part of roots; $(\bullet)$ and $(\mathrm{O})$ indicate results of experiments 1 and 2, respectively. Values are means \pm SE of 10 replicates of one plant each. Observations were taken on five 2-cm-long root segments for each plant. have antifeedant and deterrent effects against generalist herbivores (Van Dam et al. 1995). Water leachate of hound's-tongue leaves and embryos has been reported to exert allelopathic influence on associated rangeland grasses (Furness et al. 2008; Rashid et al. 2005). Whether SMS influences poisoning and/or allelopathic potential of leaves of this weed remains to be investigated.

Effect of Soil Moisture Level on Mycorrhizal Colonization. The results of this study show that SMS has a strong negative influence on mycorrhizal colonization and arbuscule and vesicle abundance in hound's-tongue roots. Soil moisture level influenced mycorrhizal colonization significantly $(\mathrm{P} \leq 0.001)$ in both experiments (Figure 4A). It increased linearly as soil moisture level increased from 40 to $100 \%$ FC (Figure 4A). Mycorrhizal colonization of roots of plants grown under $100 \%$ FC was 6-fold higher compared with those grown at $40 \%$ FC. Similarly, arbuscule and vesicle abundance also increased as soil moisture level increased from 40 to $100 \% \mathrm{FC}$ in both experiments $(\mathrm{P} \leq 0.001)$ (Figure 4B, C). Mycorrhizal colonization and arbuscule and vesicle abundance were generally lower in the second experiment compared with the first, and the increase in arbuscule abundance with increasing soil moisture level appeared to be curvilinear in both experiments. Interestingly, the magnitude of impact of SMS was greatest on mycorrhizal colonization, followed by arbuscule and vesicle abundance, in that order. This could be because the fungus colonizes the roots first, forms arbuscules, and then vesicles, which are storage structures particularly for lipids (Peterson et al. 2004). The influence of SMS on mycorrhizal colonization could be due to a drought-induced reduction in the supply of photosynthate from the shoot to the roots, production of a messenger in the shoot that is transmitted to the roots, a direct effect on the roots, hyphal desiccation in dry soil, inhibition of fungal spore germination in soil, and/or inhibition of root infection (Augé 2001; Querejeta et al. 2007). Pyrrolizidine alkaloids have been reported to inhibit fungal mycelium growth ( $\mathrm{Hol}$ and van Veen 2002). Whether alkaloids found in hound's-tongue are involved in the influence of SMS on mycorrhizal colonization of its roots or in the allelopathic effect of this weed on its neighbors remains to be investigated. Regardless of the mechanism involved, a reduction of mycorrhizal colonization of roots of this weed by SMS in combination with a decrease in root biomass can reduce competitive ability of this weed against its neighbors. 
The effect of mycorrhizal colonization on competitive interaction of hound's-tongue with associated species would, of course, depend on the species present in the mixture (mycorrhizal vs. nonmycorrhizal) and their response to mycorrhizal colonization (Allen and Allen 1984, 1990; Benjamin and Allen 1987; Crush 1974; Fitter 1977; Hall 1978; Harnett et al. 1993; West 1996).

This study characterizes the influence of SMS on seedling growth and mycorrhizal colonization of hound's-tongue roots, which can potentially affect the weed's survival, competition and allelopathic interactions, root functions, fecundity, persistence, and biological control. The results of this study show that SMS influences a variety of plant growth parameters and mycorrhizal colonization of roots in hound's-tongue, a serious rangeland weed of BC. These effects include reductions in total biomass, fresh and dry weight of shoots and roots, leaf area, SLW (leaf dry weight per unit leaf area), leaf number and petiole length, percent mycorrhizal colonization, and the abundance of arbuscules and vesicles in the colonized parts of the root. These effects may impact interaction of hound's-tongue with its nonmycorrhizal neighbors or with species that are mycorrhizal but affected to a different extent by the SMS compared with this weed.

\section{Acknowledgments}

We thank the Natural Sciences and Engineering Research Council of Canada and the Brigadier Bostock Memorial Fund for financial support, and Valerie LeMay, Professor, Forest Resources and Management, University of British Columbia, for help with statistical analysis.

\section{Literature Cited}

Allen EB, Allen MF (1984) Competition between plants of different successional stages: mycorrhizae as regulators. Can J Bot 62:2625-2629

Allen EB, Allen MF (1990) The mediation of competition by mycorrhizae in successional and patchy environments. Pages 367-389 in Grace JB, Tilman D, eds. Perspectives on Plant Competition. San Diego, CA: Academic Press

Augé RM (2001) Water relations, drought and vesiculararbuscular mycorrhizal symbiosis. Mycorrhiza 11:3-42

Baker DC, Smart RA, Ralphs M, Molyneux RJ (1989) Hound'stongue (Cynoglossum officinale) poisoning in a calf. J Am Vet Med Assoc 195:929-930

Barea J, Pozo MJ, Azcon R, Azcon-Aguilar C (2005) Microbial co-operation in the rhizosphere. J Exp Bot 56: $1761-1778$
Boomsma CR, Vyn TJ (2008) Maize drought tolerance: potential improvements through arbuscular mycorrhizal symbiosis? Field Crops Res 108:14-31

Boorman LA, Fuller RM (1984) The comparative ecology of two sand dune biennials: Lactuca virosa L. and Cynoglossum officinale L. New Phytol 69:609-629

Bray EA (1997) Plant responses to water deficit. Trends Plant Sci 2:48-54

Benjamin PK, Allen EB (1987) The influence of VA mycorrhizal fungi on competition between plants of different successional stages in sagebrush grassland. Page 144 in Sylvia DM, Hung LL, Graham JH, eds. Mycorrhizae in the Next Decade, Practical Application and Research Priorities. Gainesville, FL: Institute of Food and Agricultural Sciences

Busso CA, Bolletta A, Flemmer AC, Montani T (2008) Influence of soil water status on arbuscular mycorrhizas in three perennial grasses in central Argentina. Ann Bot Fennici 45:435-447

Cao M, Wu Q, Zou Y (2013) An improved ink-acetic acid technique for staining arbuscular mycorrhizas of citrus. Int $\mathrm{J}$ Agr Biol 15:386-388

Chaves MM, Pereira JS, Maroco J, Rodrigues ML, Ricardo CPP, Osório ML, Carvalho I, Faria T, Pinheiro C (2002) How plants cope with water stress in the field? Photosynthesis and growth. Ann Bot 89:907-916

Crush JR (1974) Growth responses to vesicular-arbuscular mycorrhiza in herbage legumes. New Phytol 73:743-749

De Jong TJ, Klinkhamer PGL (1988) Population ecology of the biennials Cirsium vulgare and Cynoglossum officinale in a coastal sand-dune area. J Ecol 76:366-382

Furness NH, Adomas B, Dai Q, Li S, Upadhyaya MK (2008) Allelopathic influence of houndstongue (Cynoglossum officinale) and its modification by UV-B radiation. Weed Technol 22:101-107

Fitter AH (1977) Influence of mycorrhizal infection on competition for phosphorus and potassium by two grasses. New Phytol 79:119-125

Gange AC, Bower E, Stagg PG, Aplin DM, Gillam AE, Bracken M (1999) A comparison of visualization techniques for recording arbuscular mycorrhizal colonization. New Phytol 142:123-132

Hall IR (1978) Effects of endomycorrhiza on the competitive ability of white clover. New Phytol 21:509-515

Harnett DC, Hetrick BAD, Wilson GTW, Gibson DJ (1993) Mycorrhizal influence of intra- and inter-specific neighbourhood interaction among co-occurring prairie grasses. J Ecol 81:787-795

Hol WHG, van Veen JA (2002) Pyrrolizidine alkaloids from Senecio jacobaea affect fungal growth. J Chem Ecol 28:1763-1772

Hsiao TC (1973) Plant responses to water stress. Ann Rev Plant Physiol 24:519-570

Johansson JF, Paul LR, Finlay RD (2004) Microbial interactions in the mycorrhizosphere and their significance for sustainable agriculture. FEMS Microb Ecol 48:1-13

Kaya C, Higgs D, Kirnak H, Tas I (2003) Mycorrhizal colonization improves fruit yield and water use efficiency in watermelon (Citrullus lanatus Thunb.) grown under wellwatered and water-stressed conditions. Plant Soil 253:287-292

Knight AP, Kimberling CV, Stermitz FR, Roby MR (1984) Cynoglossum officinale (hound's-tongue) — a cause of pyrrolizidine alkaloid poisoning in horses. J Am Vet Med Assoc 184: 647-650

Mattson W, Haack R (1987) Role of drought in outbreaks of plant-eating insects. BioScience 37:110-118 
Momayyezi M (2012) The effect of soil moisture stress on allelopathic influence of hound's-tongue (Cynoglossum officinale L.). M.Sc. Thesis, Univ. of British Columbia, Vancouver, Canada. $74 \mathrm{p}$

Moran PJ, Showler AT (2005) Plant responses to water deficit and shade stresses in pigweed and their influence on feeding and oviposition by the beet armyworm (Lepidoptera; Noctuidae). Environ Entomol 34:929-937

Pendleton RL, Smith BN (1983) Vesicular-arbuscular mycorrhizae of weedy and colonizer plant species at disturbed sites in Utah. Oecologia 59:296-301

Peterson RL, Massicotte HB, Melville LH (2004) Mycorrhizas: Anatomy and Cell Biology. Wallingford, Oxon, UK: CABI Publishing. $173 \mathrm{p}$

Prins AH, Nell HW, Klinkhamer PGL (1992) Size-dependent root herbivory on Cynoglossum officinale. Oikos 65:409-413

Querejeta JI, Egerton-Warburton LM, Allen MF (2007) Hydraulic lift may buffer rhizosphere hyphae against the negative effects of severe soil drying in a California Oak savanna. Soil Biol Biochem 39:409-417

Rashid A, Furness NH, Upadhyaya MK, Ellis BE (2005) Inhibition of seed germination and seedling growth by hound's-tongue (Cynoglossum officinale L.) seed leachate. Weed Biol Manag 5:143-149

Rowell-Rahier M (1984) The food plant preferences of Phratora vitellinae (Coleoptera: Chrysomelidae). Oecologia 64:369-374

Subramanian KS, Charest C, Dwyer LM, Hamilton RI (1995) Arbuscular mycorrhizas and water relations in maize under drought stress at tasselling. New Phytol 129:643-650

Tremmel DC, Bazzaz FA (1993) How neighbor canopy architecture affects target plant performance. Ecology 74:2114-2124

Tiritilli ME, Thompson JN (1988) Variation in swallowtail/ plant interactions; host selection and the shapes of survivorship curves. Oikos 53:153-160

Trouvelot A, Kough JL, Gianninazzi-Pearson V (1986) Mesure du taux de mycorhization VA d' un systeme radiculaire. Recherche de methods d' estimation ayant une signification fonctionnelle. Pages 217-221 in Gianinazzi-Pearson V,
Gianinazzi S, eds. Physiological and Genetic Aspects of Mycorrhizae. Paris, France: INRA

Upadhyaya MK, Cranston R (1991) Distribution, biology, and control of hound's-tongue in British Columbia. Rangelands 13:103-106

Upadhyaya MK, Furness NH (1994) Influence of light intensity and water stress on leaf surface characteristics of Cynoglossum officinale, Centaurea spp., and Tragopogon spp. Can J Bot 72:1379-1386

Upadhyaya MK, Tilsner HR, Pitt MD (1988) The biology of Canadian weeds. 87. Cynoglossum officinale L. Can J Plant Sci 68:763-774

Van Dam NM, Vuister LWM, Bergshoeff C, de Vos H, van Der Meijden HV (1995) The "raison d'etre" of pyrrolizidine alkaloids in Cynoglossum officinal: deterrent effects against generalist herbivores. J Chem Ecol 21:507-523

van der Meijden E, Wijn M, Verkaar HJ (1988) Defence and regrowth, alternative plant strategies in the struggle against herbivores. Oikos 51:355-363

Weijschedé J, Martínková J, de Kroon H, Huber H (2006) Shade avoidance in Trifolium repens: costs and benefits of plasticity in petiole length and leaf size. New Phytol 172:655-666

West HM (1996) Influence of arbuscular mycorrhizal infection on competition between Holcus lanatus and Dactylis glomerata. J Ecol 84:429-438

White TCR (1984) The abundance of invertebrate herbivores in relation to the availability of nitrogen in stressed food plants. Oecologia 63:90-105

Wu QS, Xia RX (2006) Arbuscular mycorrhizal fungi influence growth, osmotic adjustment and photosynthesis of citrus under well-watered and water stress conditions. J Plant Physiol $163: 417-425$

Received April 7, 2016, and approved August 8, 2016.

Associate Editor for this paper: Hilary A. Sandler, University of Massachusetts. 